\title{
Investigating the Effects of Marriage and Relationship Education on Couples' Communication Skills: A Meta-Analytic Study
}

Victoria L. Blanchard

SUNY Albany

Alan J. Hawkins

Brigham Young University - Provo, hawkinsa@byu.edu

Scott A. Baldwin

Brigham Young University - Provo

Elizabeth B. Fawcett

Brigham Young University - Provo

Follow this and additional works at: https://scholarsarchive.byu.edu/facpub

Part of the Other Social and Behavioral Sciences Commons

\section{Original Publication Citation}

Blanchard, V. L., Hawkins, A. J., Baldwin, S. A., \& Fawcett, E. B. (2009). Investigating the effects of marriage and relationship education on couples' communication skills: A meta-analytic study. Journal of Family Psychology, 24, 203-214.

\section{BYU ScholarsArchive Citation}

Blanchard, Victoria L.; Hawkins, Alan J.; Baldwin, Scott A.; and Fawcett, Elizabeth B., "Investigating the Effects of Marriage and Relationship Education on Couples' Communication Skills: A Meta-Analytic Study" (2009). Faculty Publications. 4226.

https://scholarsarchive.byu.edu/facpub/4226

This Peer-Reviewed Article is brought to you for free and open access by BYU ScholarsArchive. It has been accepted for inclusion in Faculty Publications by an authorized administrator of BYU ScholarsArchive. For more information, please contact ellen_amatangelo@byu.edu. 


\title{
Investigating the Effects of Marriage and Relationship Education on Couples' Communication Skills: A Meta-Analytic Study
}

\author{
Victoria L. Blanchard \\ State University of New York at Albany
}

\author{
Alan J. Hawkins, Scott A. Baldwin, \\ and Elizabeth B. Fawcett \\ Brigham Young University
}

\begin{abstract}
This meta-analysis probes into previous research substantiating the positive effects of marriage and relationship education (MRE) on couples' communication skills. We reviewed 97 MRE research reports that yielded 143 distinct evaluation studies. We found modest evidence that MRE functions both as a universal prevention and as a selective or indicated prevention. That is, MRE demonstrates program effects at longer term follow-ups for well-functioning couples and at postassessment and shorter term follow-ups for more distressed couples. In addition, we found that observational assessments produced larger effects than self-report assessments, although interpreting the meaning of this difference is difficult.
\end{abstract}

Keywords: marriage/relationship education, couples' communication, meta-analysis

Since 1975, more than 100 published and unpublished studies have evaluated the effect of marriage and relationship education (MRE) on couples' communication. Previous meta-analytic studies have provided evidence that MRE is generally effective in improving couples' relationships (Butler \& Wampler, 1999; Carroll \& Doherty, 2003; Hight, 2000; Reardon-Anderson, Stagner, Macomber, \& Murray, 2005). For instance, the most recent and comprehensive meta-analysis of MRE (Hawkins, Blanchard, Baldwin, \& Fawcett, 2008) found that MRE produces significant positive effects on participants' communication skills $(d=.36$ to .54$)$ and relationship quality ( $d=.24$ to .36$)$ at both immediate postassessment and follow-up. That study also found no gender differences in effects and only limited evidence of publication bias. Lower dosage programs produced weaker effects than moderate-dosage programs.

Notwithstanding the current evidence of the general efficacy of MRE, challenging questions and issues about MRE remain to be explored. For instance, although some previous meta-analyses have examined both immediate and longer term follow-up effects (Butler \& Wampler, 1999; Hawkins et al., 2008), meta-analysts have not investigated whether MRE acts as universal prevention, which prevents relationship problems by strengthening well-functioning couples' relationship skills, or as selective or indicated prevention (Mrazek \& Haggerty, 1994), which helps cou-

Victoria Blanchard, Department of Sociology, State University of New York at Albany; Alan J. Hawkins and Elizabeth B. Fawcett, School of Family Life, Brigham Young University; Scott A. Baldwin, Department of Psychology, Brigham Young University.

Corresponding author: Victoria Blanchard, Department of Sociology, State University of New York at Albany, 1400 Washington Avenue, Arts \& Sciences 351, Albany, NY 12222. E-mail: vblanchard@gmail.com ples at risk for distress or those experiencing nonclinical levels of distress enhance their relationships. In addition, the question of how assessment method (i.e., self-report versus observed measures) impacts effect sizes has not been addressed adequately. The purpose of this meta-analysis is to examine the effects of MRE more carefully and critically. Because MRE is now a tool of federal and state policy receiving significant public funding, it requires even greater scrutiny in evaluation (Halford, Markman, \& Stanley, 2008).

\section{Universal Prevention Versus Selective or Indicated Prevention}

The goal of MRE is to help couples form and sustain healthy, stable marriages and relationships. Most MRE programs evaluated to date appear to be oriented toward universal prevention. That is, the interventions are targeted to couples not experiencing significant distress, and their objective is to prevent future relationship problems by strengthening couples' relationship skills. However, using immediate, postprogram outcome measures to test universal prevention efficacy is inadequate (Halford et al., 2008). Although other meta-analytic work focusing on parenting interventions (Nowak \& Heinrichs, 2008) found little evidence that follow-up timing influenced effect sizes, we thought it prudent to limit a test of universal prevention to studies with follow-up assessments longer than 6 months. We conduct this more rigorous test to examine if MRE can properly be termed effective universal prevention.

Previous research has found that couples at greater risk for future relationship problems are underrepresented in MRE (Halford, O'Donnell, Lizzio, \& Wilson, 2006); yet distressed couples do participate in MRE (DeMaria, 2005). Furthermore, some evaluated MRE interventions appear to be oriented toward relationship-skill enhancement, either 
selective prevention (i.e., for those at greater risk for relationship problems) or indicated prevention (i.e., for those with elevated but nonclinical relationship problems). In fact, a great deal of work in the field is now targeting more at-risk couples (Dion \& Hawkins, 2008). In this investigation, we explore whether couples at more risk or more distress display a gain in communication skills, thus clarifying whether MRE can be termed effective selective or indicated prevention. This has not been examined in previous meta-analytic studies of MRE.

\section{Self-Report Versus Observational Assessment}

Couple communication has been assessed using either efficient self- (or partner-) report questionnaires or with more labor-intensive observational measures. The method of assessment may be a significant moderator of MRE effects. Butler and Wampler (1999) reviewed seven evaluation studies of the Couple Communication program and found that effect sizes for observational measures of communication (post $d=.95$; follow-up $d=.69$ ) were significantly larger than for self-report measures (post $d=.21$; follow-up $d=.08$ ). Similarly, Hahlweg and Markman (1988) reviewed seven cognitive-behavioral premarital intervention programs that employed both observational and self-report measures and also found stronger effects for observational $(d=1.51)$ versus self-report measures $(d=$ .52 ). Accordingly, they recommended the use of observational measures when evaluating MRE programs because the proximal goals of the programs are to modify couples' communication patterns, and ceiling effects may limit the changes that can be demonstrated by self-report measures. These meta-analyses, however, reviewed only a few MRE studies. Examining differences between self-report and observational measures should be done with all available MRE evaluation studies, which we do in this study.

Nevertheless, interpreting the potential differences between self-report and observed measures of couple communication is a complex task because these different methods may not assess the same construct. Self-report communication questionnaires generally consist of items that ask individuals to reflect in a general way about their communication patterns as a couple. For example, one of the most commonly used self-report questionnaires in evaluation studies of MRE programs is the Marital Communication Inventory (MCI; Bienvenu, 1970), which includes items such as, "Does your spouse insult you when he (she) gets angry with you?" (p. 28). As Lorenz and his colleagues (Lorenz, Melby, Conger, \& Xu, 2007) pointed out, these kinds of self-reports then, are context and issue nonspecific and tap into "more heterogeneous and amorphous circumstances" (p. 506), which may reflect participants' "efforts to average their behaviors over recent weeks, or to recall the more salient of these behaviors, and in either case, may reflect efforts to weigh their behaviors to account for the life-long meanings couples attach to their behaviors" ( $p$. 507). Self-report questionnaire data "may reflect a mixture of events and interactions that are recalled more or less vividly and then imbued with meanings that emerged over the life of the relationship" (Lorenz et al., 2007, p. 500). In short, self-report measures likely tap into individuals' general schema about overall couple interaction patterns.

In contrast, observational measures of communication behaviors may tap into a somewhat different construct. For instance, one of the most common coding systems used in the assessment of couples' communication is the Marital Interaction Coding Scheme (MICS; Hops, Wills, Patterson, $\&$ Weiss, 1972). As is done in most other observational coding systems, the MICS requires couples to be videotaped while engaging in a 10-min conversation about a problem they have identified in their relationships (Floyd, O'Farrell, \& Goldberg, 1987). The behavior displayed in a particular conversation likely includes both typical behaviors and behaviors that are idiosyncratic to the specific context (Lorenz et al., 2007). Moreover, the researchers, not the participants, interpret the meaning of the behaviors. Furthermore, the context for this behavior is constructed and observed by researchers, and studies have suggested that couples are less negative in laboratory settings than they are in other settings (Heyman, 2001). Although specific observations seem to be modestly correlated with couples' overall communication patterns (Kelly, Fincham, \& Beach, 2003), still the generalizability of any context-specific interaction may be limited.

In short, observational measures of communication are highly contextualized whereas self-report measures likely reflect general, personal schema. A general schema about interaction patterns assessed by self-report measures may involve perceptions and interpretations that are more resistant to short-term change, whereas observed measures of specific communication behavior about a specific issue is more contextual and subject to greater change. Thus, outcome evaluations employing observational measures are likely to produce larger effect sizes.

The gap between observational and questionnaire assessments also may be related to issues of social desirability and perception bias (Lorenz et al., 2007). Observational data are collected by well-trained coders who are strictly following measurement protocols (Lorenz et al., 2007). Thus, researchers are typically coding the communication behaviors taught in their interventions (often by coders also familiar with the content of the intervention program), and the demonstration of these behaviors may reflect participants' desire to impress researchers by demonstrating their new techniques (Heyman, 2001). Self-report questionnaire data could be prone to similar bias if individuals report their knowledge of learned techniques rather than reflecting on how well they are implementing them (Heyman, 2001). However, because self-report measures likely tap into a more general schema about overall communication patterns, perhaps this bias is less of an issue for self-reports than it is for observational measures.

It should not be surprising, then, to find significant differences between observational and self-report questionnaire data. One way to minimize this difference, of course, would be to have couples report on a specific conversation about a specific problem rather than reflect on their overall communication patterns. Indeed, when this is done, obser- 
vational and questionnaire data are more highly correlated than past research suggests (Lorenz et al., 2007). When the context of observational and questionnaire data is shared, they correlate as strongly as any combination of correlations among questionnaire reports (Lorenz et al., 2007). Unfortunately, to date in MRE research, there are no evaluation studies that use context-specific self-reports of couple communication, nor are there any studies that obtain a more representative sample of observed interactions across diverse contexts. Accordingly, our study can only highlight any systematic differences between self-report and observational methods in MRE outcome evaluation research; it cannot yet empirically explain the reasons for any differences found.

Observational measures do not necessarily yield larger effects than self-report measures, however. Although comparisons of self-report and observational MRE evaluation data to date have not reflected this pattern (e.g., Butler \& Wampler, 1999; Hahlweg \& Markman, 1988), self-report measures may actually be more sensitive when researchers are assessing low-incidence behaviors. Nowak and Heinrichs (2008) conducted a meta-analysis of the Triple-P parenting program and found that the intervention effects were smaller when assessed with observational measures than with other kinds of reports. They speculated that lowprevalence (child) behaviors are unlikely to be captured in brief observational measures. Instead, these infrequent behaviors may be better reported by parents who observe a child's behavior across a greater span of time and circumstances. Hence, if low-incidence communication behaviors are being assessed in MRE evaluation research, then selfreport measures may be better indicators of skill acquisition.

The current meta-analysis will examine the following two questions: (a) Are MRE programs capable of acting both as a universal prevention by preventing deterioration of communication skills over time in well-functioning couples, and as a selective or indicated prevention by enhancing skills both short- and long-term for more distressed couples? (b) Do self-reports and observed assessments of communication skills yield similar or different estimates of the effects of MRE programs? We will answer these questions by conducting separate analyses for experimental, quasiexperimental, and one-group/pre-post studies. To test MRE as universal prevention, we will limit analyses to studies with at least 7-month follow-ups. To test MRE as selective or indicated prevention, we will limit analyses to studies that had samples with a substantial proportion of couples reporting preprogram relationship distress.

\section{Method}

This investigation is part of a comprehensive metaanalysis of MRE evaluation research conducted from 1975 through 2006 (see Hawkins et al., 2008). Of the 124 codable reports identified by this larger meta-analysis, the current meta-analysis limits its analyses to 97 reports (e.g., journal articles, dissertations) of research evaluating the effect of MRE on couples' communication. However, rather than reporting the general effects of MRE on communication, these analyses provide in-depth information on the moderating effects of extended follow-up assessment, sample distress, and assessment method. Some of these reports used distinct samples to examine more than one intervention, and these distinct samples were each considered as separate studies (Lipsey \& Wilson, 2001). Thus, the current metaanalysis represents the results of 143 distinct studies of the effects of MRE on couples' communication.

However, the number of studies reported for a particular statistic will be much smaller than this number for a number of reasons. First, we conduct analyses separately for experimental $(k=41)$, quasi-experimental $(k=50)$, and onegroup/pre-post studies $(k=52$; see Selection and Inclusion Criteria: Study design). The number of studies used in a particular set of analyses will also depend on the number of studies available for a given timing or method of assessment. There were only five experimental, two quasiexperimental, and seven one-group/pre-post studies that reported follow-ups beyond 6 months. There were only four experimental and three one-group/pre-post studies that had samples with a significant proportion of distressed couples. (Quasi-experimental studies, on average, had samples reporting lower satisfaction than average, indicating the presence of more distressed couples.)

\section{Literature Search}

We identified studies by reviewing the reference lists of previous meta-analyses and the search list from a recent MRE meta-analysis (i.e., Reardon-Anderson et al., 2005). We also conducted searches with PsychInfo and Dissertation Abstracts International. Also, we contacted many researchers and practitioners over a 2-year period to find unpublished reports. Although we did not do a specific search for studies in non-English languages, we did come across five such studies in our search. We employed translators to help us with the coding of these studies.

\section{Selection and Inclusion Criteria}

Psychoeducational couple intervention. All studies assessed the effects of a psychoeducational intervention that attempted to improve couple relationships. Three studies evaluated communication skills taught to high school students but not to couples in relationships; we excluded these studies from our analyses (Adler-Baeder, Kerpelman, Schramm, Higginbotham, \& Paulk, 2007; Gardner \& Boellaard, 2006; Gardner, Giese, \& Parrot, 2004). Therapeutic interventions were excluded to provide a clear picture of the effects of psychoeducational intervention. This is an important conceptual and methodological consideration because therapeutic interventions generally have stronger effects than psychoeducational interventions (Shadish \& Baldwin, 2003).

Reporting of outcome data. For inclusion in the current meta-analysis, studies had to report effects using quantitative methods that could produce an effect size. Some quantitative studies did not report the data necessary to calculate an effect size, such as group size, means, or standard devi- 
ations. However, using various techniques, we succeeded in "rehabilitating" a limited number of these by following recommendations outlined in Lipsey and Wilson (2001). Yet, six published and five unpublished studies were excluded from analyses because rehabilitation or contacting the author for more information was not possible.

Study design. We included both experimental and quasi-experimental evaluation studies. Experimental studies included a randomized no-treatment control group, whereas quasi-experimental studies included a nonrandomized, notreatment control group. A no-treatment control group was defined as a group that did not receive an intervention comparable to mainstream MRE in content or intensity. When control groups administered interventions comparable in time or intensity to mainstream MRE, they were coded as treatment groups. (In this case, what may have been designed and reported in a research article or dissertation as one experimental study was coded as multiple, one-group pre-post studies; e.g., Halford, Sanders, \& Behrens, 2001.) Wait-list control groups were coded as notreatment control groups as long as appropriate preintervention data were collected. This was done to make use of all available MRE evaluation information and to standardize the comparison between treatment and notreatment. For technical and conceptual reasons (such as self-selection into treatment groups), analyses were conducted and reported separately for each design group (see Lipsey \& Wilson, 2001; Shadish, Matt, Navarro, \& Phillips, 2000).

In addition, to get as complete a picture of MRE intervention as possible, we included studies employing onegroup pre-post designs in our investigation as a supplement to analyses of controlled studies. Included in the one-group pre-post studies are a number of reports that compared one MRE intervention to another with two independent samples. In these cases, we coded each treatment separately as a one-group pre-post study. The one-group pre-post studies generally were conducted with otherwise sound methods, so ignoring them would have excluded an important body of evaluation work and potentially limited our understanding of the practice of MRE, especially if these studies are more representative of MRE in field (as opposed to laboratory) conditions, a distinct possibility. (One third of these studies were conducted in community settings, such as churches, where obtaining a no-treatment comparison group is more difficult, see Laurenceau, Stanley, Olmos-Gallo, Baucom, \& Markmam, 2004).

We acknowledge, however, potential problems associated with using one-group pre-post studies. First, a precise effect size calculation requires the correlation between the pre-post assessments, information that was seldom reported. Often in these circumstances, meta-analysts reasonably estimate the correlation to be .50 (Schwartz et al., 2006), which we did in our study. In a meta-analysis of parenting education interventions, Nowak and Heinrich (2008) reconstructed a reasonable pre-post correlation from other statistical information in reports and found an average correlation of .54. In sensitivity analyses (not reported here), we found that using estimates of the correlations from .40 to 60 did not substantially change the effects.

A second concern is that it is inappropriate to mix onegroup pre-post or change-score effects sizes with groupdifference effect sizes both because they are calculated with different formulae and because there may be unknown systematic differences between these different designs (Lipsey \& Wilson, 2001). Accordingly, we report effect sizes from one-group pre-post studies separate from those with experimental and quasi-experimental studies, and do so as a supplement to group-difference analyses to see if they produce similar patterns of findings. We are interested in the pattern of findings rather than the precise estimate of the one-group pre-post effect sizes because, as mentioned above, there could be systematic differences that bias these effects, although the direction of that bias can go either way (Nowak \& Heinrichs, 2008).

Publication status. Both published and unpublished studies were included to directly address publication bias. Baldwin and Shadish (2006) found that meta-analyses that ignore unpublished studies overstate the true effect size by an estimated $5 \%$ to $20 \%$. Of the 97 reports analyzed in this study, 42 were published reports and 55 were unpublished reports, most of which were doctoral dissertations. The fact that there were more unpublished than published reports of MRE programs diminishes the specter of publication bias, and in analyses reported elsewhere (Hawkins et al., 2008), there was only minor evidence of publication bias. Still, including unpublished studies should yield a less biased estimate of the true effects of MRE.

Timing of assessment. Earlier meta-analyses found that communication skills may deteriorate at follow-up (Butler \& Wampler, 1999; Reardon-Anderson et al., 2005), although the most recent, comprehensive meta-analysis found little deterioration (Hawkins et al., 2008). Conducting analyses on extended follow-up assessments allowed us to address the question of whether communication training sustained effects beyond immediate postassessments or short-term follow-ups. For these analyses, we included only assessments that occurred at least 7 months after the conclusion of the intervention. This benchmark is consistent with the standards of evidence published by the Society for Prevention Research, which specifies that to establish program efficacy for outcomes that may deteriorate over time, there must be at least one study with a follow-up assessment greater than or equal to 6 months (Flay et al., 2005).

Level of relationship distress. To examine whether MRE functions as a selective or indicated prevention, we were interested in identifying the relative distress level of the samples in the studies included in our meta-analysis. Overall, only 79 out of 143 studies $(55 \%)$ reported the distress level of their samples. To determine whether individuals were distressed, most researchers measured whether pretreatment relationship quality scores were below established cut-offs on standardized instruments, such as the Marital Adjustment Test (e.g., Durana, 1996b). For experimental and one-group pre-post studies that reported this information (53\%), we were interested in analyzing those studies in which a significant proportion of the sample was 
distressed, operationalized as $26 \%$ to $100 \%$, (7 of 49 studies). For quasi-experimental studies, the treatment groups were significantly lower than control groups at pretest for both relationship quality $\left(d_{q e}=-.153, p<.05\right)$ and communication skills $\left(d_{q e}=-.178, p<.01\right)$. Accordingly, we were able to use these studies as a proxy for somewhat more distressed couples.

\section{Variable Coding}

A 55-item codebook was created to code moderators relevant to the effects of MRE. Many of the codes reflected dimensions of MRE identified in the Comprehensive Framework for Marriage Education (Hawkins, Carroll, Doherty, \& Willoughby, 2004; e.g., program dosage). There were also a number of codes relating to the study (e.g., publication type), sample (e.g., ethnicity), and assessment methods (e.g., assessment timing). Two trained coders coded every study. The first author coded every study. Three other individuals served as the second coder. After separately coding, the two coders compared answers. When there were discrepancies, coders sought further clarification from the study text until they reached agreement. In cases in which the two coders were unable to come to a consensus, the coders discussed the differences with the second author until a consensus was reached. Thus, we did not compute intercoder reliability; rather we used coder discrepancies as a stimulus for deeper investigation into the study to ascertain objectively the correct code.

\section{Computation of Effect Size}

We computed effect sizes with Comprehensive Meta Analysis II (CMA; Biostat, 2006). Standardized mean group differences were calculated for experimental and quasiexperimental studies. The standardized mean change score was computed for one-group pre-post studies. Each effect size was weighted by the inverse variance (squared standard error) to account for the precision of the effect size estimates. Hedges's (1981) correction for small sample size bias was used because many studies had small sample sizes. We report the random effects results, which are generally a more conservative estimate of effects. Meta-analytic experts now recommend random effects estimates as standard practice (Shadish \& Baldwin, 2003). As mentioned previously, we conducted analyses separately for each study-design group.

\section{Results}

\section{Descriptive Data}

The majority of studies (73\%) delivered programs targeting married (rather than premarital) couples, and most (62\%) provided a moderate dosage of 9 to $20 \mathrm{hr}$ of formal training (median length $=12.3 \mathrm{hr}$ ), although not all those hours necessarily were devoted exclusively to communication and problem-solving skills training. Couples Communication (Miller, Nunnally, \& Wackman, 1975) and interventions based on the Prevention and Relationship Enhancement Program
(Markman \& Floyd, 1980) were the most frequently evaluated programs. The mean year of publication for experimental and one-group pre-post studies was about 1993, whereas for quasiexperimental studies it was about 1987.

\section{Can MRE Programs Prevent Future Communication Problems?}

In previous analyses (Hawkins et al., 2008), we found that the experimental-design communication skills effect size associated with short-term follow-up assessments ranged from $d_{e x}=.366$ to .428 . However, only a handful of these studies conducted follow-up assessments past 6 months postintervention that would allow for more potential deterioration. For the five experimental studies that conducted follow-up assessments at 7 months or longer, the effect size was $d_{e x}=.588(p<.01)$. For the two quasiexperimental studies that conducted follow-up assessments at 7 months or longer, the follow-up effect size was $d_{q e}=$ .492 ( $n s)$. For the seven one-group pre-post design studies with follow-up assessments at 7 months or longer, the follow-up effect size was $d_{p p}=.321(p<.001)$. Even with the small number of studies with follow-up assessments greater than 6 months, there is some evidence that MRE programs can prevent deterioration of communication skills for nondistressed couples.

\section{Can MRE Programs Enhance Communication Skills for More Distressed Couples?}

We explored whether MRE programs can enhance communication skills for somewhat distressed couples. As mentioned earlier, many MRE programs are taken mostly by couples functioning well within the nondistressed range of relationship quality, and some researchers even actively screened distressed couples from their samples. A small number of MRE program studies in our meta-analysis, however, do have somewhat distressed couples in their samples. Note that many studies $(45 \%)$ did not report sample-distress levels, which limited our ability to explore this moderator of MRE effects.

Experimental studies. Four experimental studies had samples with a substantial proportion of couples (26\% to $100 \%)$ reporting preprogram relationship distress. The postassessment communication effect size for these four studies was $d_{e x}=.567(p<.001)$. At short-term follow-up, the effect size for these four studies was $d_{e x}=.646(p<.001)$. This finding is based on a small number of studies and should be interpreted cautiously, but it provides modest evidence that MRE programs can enhance immediate communication skills for somewhat distressed couples, at least in the short term. Note, however, that our analyses could underestimate or overestimate the effect size of programs oriented to somewhat more distressed couples because there were still many nondistressed couples in some of these programs.

Quasi-experimental studies. Another way we examined whether MRE programs can enhance relationship skills for somewhat more distressed couples was to examine effects 
for quasi-experimental studies. In quasi-experimental studies, individuals with greater needs may be able to, and often do, self-select into treatment rather than control groups (Shadish et al., 2000). Thus, even if the trajectories of change are positive for treatment-group participants relative to control-group participants, differences between treatment and control groups at postassessments still may be small. We tested for significant group differences for pretest scores in quasi-experimental studies, as suggested by Shadish et al. These analyses revealed that, indeed, overall, treatment groups were significantly lower than control groups at pretest for both relationship quality $\left(d_{q e}=-.153, p<.05\right)$ and communication skills $\left(d_{q e}=\right.$ $-.178, p<.01)$. That is, quasi-experimental studies, overall, had somewhat more distressed couples and poorer communicators in treatment groups than in control groups at pre-assessment. (This was not true for experimental studies, as would be expected when effective randomization procedures are employed.) Thus, investigating quasi-experimental studies indirectly allows us to explore the effects of MRE programs that employ somewhat more distressed samples.

When we estimated effect sizes for quasi-experimental studies using the standardized mean difference effect size, the effects were likely underestimated because they did not take account of initial group differences due to non-random assignment to groups (postassessment communication $d_{q e}=.227, p<.01, k=45$; follow-up $d_{q e}=$ $.146, n s, k=29)$. To deal with this challenge, we examined effect sizes for quasi-experimental studies based on postassessment group differences of pre-to-post change scores that account for potential pretest group differences. As discussed in the Method section, computing effect sizes based on change scores presented computational challenges, however, because information on the correlation between baseline and postassessments was seldom provided. As we did for computation of the one-group pre-post effect size, we used an estimated correlation of .50 in our analyses. Noting this imprecision, change score effect sizes for the treatment group were: $d_{q e}=.356, p<.001$, at postassessment; and $d_{q e}=$ $.379, p<.001$, at follow-up. Thus, examining quasiexperimental studies that tended to have slightly more distressed treatment-group couples, we found that MRE programs can produce modest, positive gains in communication skills that are maintained at short-term follow-up assessments.

One-group pre-post studies. Among nonexperimental, pre-post design studies, there were three studies that had a significant proportion (26\% to $100 \%$ ) of their samples in the distressed range. For these three studies, the postassessment effect size was $d_{p p}=1.567, p<.001$. (Unfortunately, there was only one study with a follow-up effect size.) As with the results for experimental studies, these results must be interpreted with caution because they are based on a very small number of studies and the samples of the studies also include nondistressed couples.

\section{Do Self-Report Measure Effect Sizes Differ From Observational Measure Effect Sizes?}

We conducted analyses to test for differences between self-report and observational measures of communication skills outcomes. Observational measures yielded significantly larger effects than self-report measures. For experimental studies at postassessment, $d_{e x}=.173(n s)$ for selfreport measures $(k=25)$, but $d_{e x}=.849(p<.001)$ for observational measures $(k=19)$. The difference between these effects was significant $(Q=19.58, p<.001)$. There was little deterioration of either effect size at short-term follow-up: $d_{e x}=.144(n s)$ for self-report measures and $d_{e x}=.831(p<.001)$ for observational measures. The difference between these effect sizes also was significant $(Q=9.13,1, p<.01)$.

The results for quasi-experimental studies were similar to the results for experimental studies. At postassessment, $d_{q e}=.057(n s)$ for self-report measures $(k=36)$ and $d_{q e}=$ $.651(p<.001)$ for observational measures $(k=23)$, a significant difference $(Q=20.7, p<.001)$. At short-term follow-up, $d_{q e}=.046(n s)$ for self-report $(k=21)$ and $d_{q e}=$ $.433(p<.01)$ for observational $(k=14)$. This difference between the follow-up effect sizes, however, was not quite significant $(Q=3.71, p=.054)$.

For one-group pre-post studies, at immediate postassessment, we found no significant difference between selfreport measures $\left(d_{p p}=.633, p<.001, k=28\right)$ and observational assessments $\left(d_{p p}=.720, p<.001, k=20\right.$; $Q=.89, n s)$. However, at short-term follow-up assessment, effect sizes from observational measures were significantly larger than self-report measure effects (for self-report measures, $d_{p p}=.357, p<.001, k=11$; for observational measures, $\left.d_{p p}=.607, p<.001, k=16 ; Q=9.18, p<.01\right)$.

\section{Discussion}

The purpose of this meta-analysis was to examine more critically the effects of MRE. Specifically, we sought greater clarity for the following two questions: (a) Are MRE programs capable of acting both as a universal prevention of deteriorating communication skills over time in wellfunctioning couples and also as a selective or indicated prevention by enhancing skills over both short- and longterm for more distressed couples? (b) Do self-reports and observed assessments of communication skills yield similar or different estimates of the effects of MRE programs? Answers to questions such as these are an important step in justifying any claims to the effectiveness of MRE, especially in the context of its current public funding.

Our analyses provide modest evidence that MRE functions effectively as a universal prevention; well-functioning couples improved or maintained learned communication skills compared to control-group couples (or improved relative to themselves in the case of one-group pre-post design studies) even when we limited analyses to studies with follow-up assessments greater than 6 months. Again, however, caution is needed because, unfortunately, the number of studies with longer-term follow-up assessments was 
small. A strong test of universal prevention efficacy would be to push the temporal horizon for skill maintenance even further, to 2 to 3 years, which only a couple of small-sample studies have done. Fortunately, major studies with large samples followed for 3 or more years are in the professional pipeline.

In addition, examining a small set of MRE evaluation studies that included couples experiencing some relationship distress, we found modest evidence that MRE can function as a selective or indicated prevention by producing significant program effects for communication skills. This is encouraging news to policy makers who now are funding MRE services targeted to lower income couples with greater relationship needs and communication challenges. Caution is needed, however, because these findings are based on a small set of studies to date. Fortunately, researchers are currently conducting more studies with large and diverse samples of lower income and more distressed couples, so these results soon will be available (Halford et al., 2008). In addition, there is growing evidence in the related area of parent training programs that distressed families gain even more than nondistressed families from these kinds of prevention programs (Nowak \& Heinrichs, 2008).

Our modest findings that MRE programs can enhance communication skills among couples with distress and relationship challenges are reinforced by some recent published studies not included in our study. Cummings, Faircloth, Mitchell, Cummings, and Schermerhorn (2008) evaluated the effects of an MRE program on a sample in which nearly half of couples were distressed and found short- and long-term reductions in marital conflict and improvements in marital quality. In addition, a recently conducted but still unpublished randomized trial (Cowan, Cowan, Pruett, \& Pruett, 2007) suggested that MRE can produce positive relationship outcomes for lower income, ethnically diverse couples in California (67\% were below the poverty line).

MRE, then, appears to be capable of functioning as universal, selective, and indicated prevention. This is encouraging because, as Weissberg, Kumpfer, and Seligman (2003) noted, there is a dilemma in the prevention field of how to balance the need for universal prevention programs provided to all interested individuals with the need for selective or indicated prevention programs designed to serve more at-risk or distressed individuals. Rishel (2007) urged prevention scholars "to implement and evaluate comprehensive prevention programs that aim at promoting and enhancing ... mental health while still targeting those most at risk" (p. 161). There is mounting evidence that comprehensive prevention programs can be effective at both these goals (Nowak \& Heinrichs, 2008; Weissberg et al., 2003).

Our second research question addressed how MRE effects are assessed; that is, whether self-report and observational measures of communication skills produce similar results. In most comparisons, observational measures produced significantly larger effect sizes than self-report measures. Also, it is interesting to note that in every case, effect sizes for observational data were significant, yet self-report effect sizes were significant only for one-group pre-post studies.

Interpreting these results is challenging. As we noted earlier, observational and self-report measures may assess different constructs. Observational measures may better indicate whether couples have been able to incorporate specific communication skills and techniques into their behavioral repertoire, at least as they discuss a specific issue within a specific context. Thus, observational measures may be more sensitive to whether program participants learned a targeted skill. However, behavioral observations may be less effective at assessing whether learned communication behaviors are generalized across the diverse contexts and situations couples experience in their everyday lives to produce a personal schema of effective interaction. Selfreport measures, on the other hand, may be better at tapping into a personal schema of how well couples are able to interact, communicate, and resolve problems in daily life.

One interpretation of our results is that MRE appears to be capable of changing couples' communication behavior in a specific context, but couples may not be generalizing that behavior to interaction in their relationships. Research has found that couples show less negativity in observed contexts than in naturalistic settings, so the large effect sizes produced for observed assessments may reflect reactivity effects (Heyman, 2001). This could be an issue particularly where researchers select only those codes from a coding system that capture the skills taught in their MRE interventions (e.g., Adam \& Gringas, 1982). The fact that we found no evidence of deterioration of effect sizes from postassessments to short-term follow-up assessments for observed measures makes inflation due to reactivity effects less likely, but it is still possible. Of course, one possibility is that the communication and problem-solving skills emphasized in MRE are not relevant to day-to-day couple interactions. Indeed, some researchers have criticized the utility of some of these skills, such as active listening, noting that couples appear not to make good use of them in everyday life (Gottman, Coan, Carrere, \& Swanson, 1998; Spitzberg, 2003). In contrast, another possibility is that skills such as active listening may act as important, albeit temporary, "scaffolding" that provides couples with external support while they develop more internal mechanisms for enhancing their relationships (Stanley, Bradbury, \& Markman, 2000).

Our meta-analysis cannot determine which of these explanations for the difference between self-report and observational measures is valid. We need data from contextspecific self-report measures and observational methods that sample a much broader range of everyday circumstances, issues, and times to see if context-specific behaviors are generalized. For example, one team of University of California at Los Angeles researchers (Ochs, Graesch, Mittmann, Bradbury, \& Repetti, 2006) videorecorded family interactions in participants' homes, cars, and other settings on multiple occasions and times to investigate family cohesion. MRE evaluation researchers could invest in the use of video ethnography to observe family members in naturalistic settings, sampling several distinct time periods to capture everyday conversations and interactions. 
Until we have new data reflecting some of these methods and measures, we cannot confidently interpret the meaning of the different outcomes produced by self-report and observational methods. Thus, for now it seems wise for MRE researchers to invest in collecting both self-report and observational assessments rather than to assume one measure is superior. Both assessment methods may have merit to MRE researchers and practitioners. Practitioners need to know if couples can learn complex new skills, and observational methods may be unbiased indicators of an ability to reproduce learned communication behaviors in a specific context. Practitioners hope that skills learned in their programs are implemented across a wide spectrum of communication challenges in everyday family life, not just in their laboratories. Self-report measures may represent a fair test of whether this goal has been achieved.

Past program-evaluation studies, as well as systematic meta-analyses, have asked the question, "Does MRE work?" There is mounting evidence that, in general, it does. This meta-analysis sought greater detail and depth to answer this question. We found modest evidence that MRE works not only as a universal prevention but also as a selective or indicated intervention. We also found that couples are capable of displaying learned communication behavior to trained researchers in specific problem-solving exercises. Less clear, however, is whether couples incorporate those skills effectively into their everyday communication challenges. Future research needs to be designed to clarify this important question.

\section{References}

References marked with an asterisk indicate coded evaluation studies.

*Adam, D., \& Gingras, M. (1982). Short- and long-term effects of a marital enrichment program upon couple functioning. Journal of Sex \& Marital Therapy, 8, 97-118.

Adler-Baeder, F., Kerpelman, J. J., Schramm, D., Higginbotham, B. J., \& Paulk, G. A. (2007). The impact of relationship education on adolescents of diverse backgrounds. Family Relations, 56, 291-230.

*Anderson, L. D. (1984). The effects of a home-based, audio cassette marriage enrichment course on marital communication and marital adjustment (Doctoral dissertation, North Texas State University, 1984). Dissertation Abstract International, 45, 1989A.

*Avery, A. W., Ridley, C. A., Leslie, L. A., \& Milholland, T. (1980). Relationship enhancement with premarital dyads: A sixmonth follow-up. The American Journal of Family Therapy, 8, 23-30.

*Bagarozzi, D. A., Bagarozzi, J. I., Anderson, S. A., \& Pollane, L. (1984). Premarital education and training sequence (PETS): A 3-year follow-up of an experimental study. Journal of Counseling and Development, 63, 91-100.

Baldwin, S. A., \& Shadish, W. R. (2006). Publication bias in meta-analyses (Working paper). Provo, Utah: Brigham Young University.

*Baughman, D. A. (1981). The effect of self-esteem, relationship satisfaction, conceptual complexity and present relationship communication patterns on the learning of communication skills: A field study (Doctoral dissertation, University of Illinois, 1981). Dissertation Abstracts International, 42, 3910A.
*Beaver, W. A. (1978). Conjoint and pseudo-disjunctive treatment in communication skills for relationship improvement with marital couples (Doctoral dissertation, Marquette University, 1978). Dissertation Abstracts International, 39, 3361A-3362A. (UMI No. 78-2, 4332)

*Biderman, R. (1982). The effects of the Minnesota Couples Communication Program on communication, adaptability and cohesion: A quasi-experimental investigation (Doctoral dissertation, University of Minnesota, 1982). Dissertation Abstracts International, 43, 2600A.

Bienvenu, M. J., Sr. (1970). Measurement of marital communication. The Family Coordinator, 56, 153-181.

Biostat. (2006). Comprehensive meta-analysis Version 2.2 [Computer software]. Englewood, NJ: Author.

*Bodenmann, G., Charvoz, L., Cina, A., \& Widmer, K. (2001). Prevention of marital distress by enhancing the coping skills of couples: 1-year follow-up study. Swiss Journal of Psychology, $60,3-10$.

*Boike, D. E. (1977). The impact of a premarital program on communication process, communication facilitativeness, and personality trait variables of engaged couples (Doctoral dissertation, The Florida State University, 1977). Dissertation Abstracts International, 38(5-A), 3083.

*Braukhaus, C., Hahlweg, K., Kröger, C., Groth, T., \& FehmWolfsdorf, G. (2001). Darf es ein wenig mehr sein? Zur Wirksamkeit von Auffrischungssitzungen bei der Prävention von Beziehungsstörungen [A little bit more? The impact of adding booster sessions to a prevention training program for marital distress]. Verhaltenstherapie, 11, 56-62.

*Breen, R. B. (1989). The effects of a communication skills workshop on dyadic adjustment in marital relationships (Doctoral dissertation, East Texas State University, 1989). Dissertation Abstracts International, 50, 1215A.

*Brock, G. W. (1978). Unilateral marital intervention: Training spouses to train their partners in communication skills (Doctoral dissertation, The Pennsylvania State University, 1978). Dissertation Abstracts International, 39(11-B), 5511-5512. (UMI No. AAT 7909049)

*Brock, G. W., \& Joanning, H. (1983). A comparison of the Relationship Enhancement Program and the Minnesota Couple Communication Program. Journal of Marital and Family Therapy, 9, 413-421.

*Brown, J. O. (1993). Effects of Adventist engaged encounter on role expectations and growth in premarital relations (Doctoral dissertation, Andrews University, 1993). Dissertation Abstracts International, 54, 2750A.

*Bryan, A. A. M. (1995). Effect of community based intervention on relationship quality in expectant parent couples (Doctoral dissertation, University of Minnesota, 1995). Dissertation Abstracts International, 56, 3689B.

*Burnham, R. A. (1984). Effects of the Couple Communication Program on marital and family communication of high and low socioeconomic status couples (Doctoral dissertation, University of Notre Dame, 1984). Dissertation Abstracts International, 45, 1006B.

*Busick, C. A. (1982). The effects of communication training on marital communication, marital satisfaction and self-concept (Doctoral dissertation, Texas A\&M. University, 1982). Dissertation Abstracts International, 43(3-A), 725. (UMI No. 8219094)

Butler, M. H., \& Wampler, K. S. (1999). A meta-analytic update of research on the Couple Communication program. The American Journal of Family Therapy, 27, 223-237.

*Carpenter, K. M. (1995). Prevention of the decline of marital 
satisfaction during the transition to parenthood: A pilot test of marital skills training workshop (Master's thesis, University of Nevada, Las Vegas, 1995). Masters Abstracts International, 34, 878.

Carroll, J. S., \& Doherty, W. J. (2003). Evaluating the effectiveness of premarital prevention programs: A meta-analytic review of outcome research. Family Relations, 52, 105-118.

*Chambers, F. A. (1986). A comparison of the effects of the Couple Communication II Program and a family of origin workshop on marital satisfaction and individual autonomy (Doctoral dissertation, The College of William and Mary, 1986). Dissertation Abstracts International, 47, 3311A.

*Cina, A., Widmer, K., \& Bodenmann, G. (2002). Die Wirksamkeit des Freiburger Stresspräventionstrainings (FSPT): Ein Vergleich von zwei Trainingsvarianten [The effectiveness of the Couple's Coping Enhancement Training (CCET): A comparison of two training versions]. Verhaltenstherapie, 12, 36-45.

*Cleaver, G. (1987). Marriage enrichment by means of a structured communication programme. Family Relations, 36, 49-54.

*Cottle, L. T. (1987). Effects of training conditions upon married couples' empathic ability, perception of spouse's empathy, marital intimacy, and marital satisfaction (Doctoral dissertation, Brigham Young University, 1987). Dissertation Abstracts International, 49, 746A.

Cowan, P. A., Cowan, C. P., Pruett, M., \& Pruett, K. (2007, June). Supporting father involvement in low-income families: Interventions for fathers and couples. Paper presented at the Administration for Children and Families Welfare Research Conference, Crystal City, VA.

*Cullen, H. F. (1985). The effects of participation in marriage encounter on marital communication and marital satisfaction (Doctoral dissertation, Temple University, 1985). Dissertation Abstracts International, 46, 2866B.

Cummings, E. M., Faircloth, W. B., Mitchell, P. M., Cummings, J. S., \& Schermerhorn, A. C. (2008). Evaluating a brief prevention program for improving marital conflict in community families. Journal of Family Psychology, 22, 193-202.

*Davis, G. M. (1979). The differential effect of married couple communication training in groups with the spouse present and spouse not present (Doctoral dissertation, The University of North Carolina, 1979). Dissertation Abstracts International, 40, 4023.

*Davis, M. W. (1995). An experimental study of the "growing together" marriage preparation program (Doctoral dissertation, Purdue University, 1995). Dissertation Abstracts International, 56, 2563A.

*Delaney, J. E. II. (1993). The effects of participation in a marital preparation program on couple compatibility (Doctoral dissertation, The University of Toledo, 1993). Dissertation Abstracts International, 55, 6701B.

DeMaria, R. M. (2005). Distressed couples and marriage education. Family Relations, 54, 242-253.

Dion, M. R., \& Hawkins, A. J. (2008). Federal policy efforts to improve outcomes among disadvantaged families by supporting marriage and family stability. In D. R. Crane \& T. B. Heaton (Eds.), Handbook of families and poverty (pp. 411-425). Thousand Oaks, CA: Sage.

*Dode, I. L. (1979). An evaluation of the Minnesota Couples Communication Program: A structured educational enrichment experience (Doctoral dissertation, Arizona State University, 1979). Dissertation Abstracts International, 40, 1211A. (UMI No. 79-20, 500)

*Duncan, S. F., Steed, A., \& Martino, C. (2006). Comparing web-based and traditional family life education on outcomes for marriage. Unpublished manuscript, Brigham Young University.

*Durana, C. (1996a). Bonding and emotional reeducation of couples in the PAIRS training: Part 2. The American Journal of Family Therapy, 24, 315-328.

*Durana, C. (1996b). A longitudinal evaluation of the effectiveness of the PAIRS psychoeducational program for couples. Family Therapy, 23, 11-36.

*Dyer, P., \& Kotrla, K. (2006). Active Military Life Skills program: AMLS final report. Communication. Waco, TX: Baylor University School of Social Work.

*Dyer, P., \& Kotrla, K. (2006). Hispanic Active Relationship project: HARP preliminary report. Waco, TX: Baylor University School of Social Work.

*Farris, D. W., \& Avery, A. W. (1980). Training marital couples in problem-solving skills: An evaluation of a weekend training format. Family Therapy, 7, 83-96.

Flay, B. R., Biglan, A., Boruch, R. F., Castro, F. G., Gottfredson, D., Kellam, S., et al. (2005). Standards of evidence: Criteria for efficacy, effectiveness and dissemination. Prevention Research, 6, 151-175.

*Floyd, F. J. (1988). Couples' cognitive/affective reactions to communication behaviors. Journal of Marriage and the Family, 50, 523-532.

Floyd, F. J., O’Farrell, T. J., \& Goldberg, M. (1987). Comparison of marital observational measures: The Marital Interaction Coding System and the Communication Skills Test. Journal of Consulting and Clinical Psychology, 55, 423-429.

Gardner, S. P., \& Boellaard, R. (2006, November). Does youth relationship education work after high school? A longitudinal study. Poster session presented at the National Council on Family Relations, Minneapolis, MN.

Gardner, S. P., Giese, K., \& Parrot, S. M. (2004). Evaluation of the Connections: Relationships and Marriage curriculum. Family Relations, 53, 521-527.

*Gottman, J., Ryan, K., Swanson, C., \& Swanson, K. (2005). Proximal change experiments with couples: A methodology for empirically building a science of effective interventions for changing couples' interaction. The Journal of Family Communication, 5, 163-190.

Gottman, J. M., Coan, J., Carrere, S., \& Swanson, C. (1998). Predicting marital happiness and stability from newlywed interactions. Journal of Marriage and the Family, 60, 5-22.

*Greene, G. J. (1985-1986). The effect of the Relationship Enhancement Program on marital communication and self-esteem. The Journal of Applied Social Sciences, 10, 78-94.

Hahlweg, K., \& Markman, H. J. (1988). Effectiveness of behavioral marital therapy: Empirical status of behavioral techniques in preventing and alleviating marital distress. Journal of Consulting and Clinical Psychology, 56, 440-447.

*Hahlweg, K., Markman, H. J., Thurmaier, F., Engl, J., \& Eckert, V. (1998). Prevention of marital distress: Results of a German prospective longitudinal study. Journal of Family Psychology, 12, 543-556.

*Halford, K. W., Moore, E., Wilson, K. L., Farrugia, C., \& Dyer, C. (2004). Benefits of flexible delivery relationship education: An evaluation of the Couple CARE Program. Family Relations, 53, 469-476.

Halford, K. W., O’Donnell, C., Lizzio, A., \& Wilson, K. L. (2006). Do couples at high risk of relationship problems attend premarriage education? Journal of Family Psychology, 20, 160-163.

Halford, W. K., Markman, H. J., \& Stanley, S. M. (2008). Strengthening couple relationships with education: Social policy 
and public health perspectives. Journal of Family Psychology, 22, 497-505.

*Halford, W. K., Sanders, M. R., \& Behrens, B. C. (2001). Can skills training prevent relationship problems in at-risk couples? Four-year effects of a behavioral relationship education program. Journal of Family Psychology, 15, 750-768.

*Hardwick, J. B. (2005). CREDO marriage enrichment retreat: Measuring program efficiency for the Canadian forces chaplaincy (Doctoral dissertation, Regent University, 2005). Dissertation Abstracts International, 66, 1809-2030.

*Harrington, C. M. (1998). A comparative evaluation of the effectiveness of two marriage preparation programs: A look at the importance of communication skill training (Doctoral dissertation, Lehigh University, 1998). Dissertation Abstracts International, 60, 366.

Hawkins, A. J., Blanchard, V. L., Baldwin, S. A., \& Fawcett, E. B. (2008). Does marriage and relationship education work? A metaanalytic study. Journal of Consulting and Clinical Psychology, 76, 723-734.

Hawkins, A. J., Carroll, J. S., Doherty, W. J., \& Willoughby, B. (2004). A comprehensive framework for marriage education. Family Relations, 53, 547-558.

*Hawley, D. R., \& Olson, D. H. (1995). Enriching newlyweds: An evaluation of three enrichment programs. The American Journal of Family Therapy, 23, 129-147.

Hedges, L. V. (1981). Distribution theory for Glasser's estimator of effect size and related estimators. Journal of Educational Statistics, 6, 107-128.

Heyman, R. E. (2001). Observation of couple conflicts: Clinical assessment applications, stubborn truths, and shaky foundations. Psychological Assessment, 13, 5-35.

Hight, T. L. (2000). Do the rich get richer? A meta-analysis of the methodological and substantive moderators of couple enrichment (Doctoral dissertation, Virginia Commonwealth University, 2000). Dissertation Abstracts International, 61, 3278B.

*Hollis, K. A. (2004). Examining the impact of a psycho-spiritual educational model of marriage enrichment on seminary couples: A pilot study (Doctoral dissertation, The Southern Baptist Theological Seminary, 2004). Dissertation Abstracts International, $65,181$.

Hops, H., Wills, T. A., Patterson, G. R., \& Weiss, R. L. (1972). Marital interaction coding system. Eugene: University of Oregon Research Institute.

*Hoskins, J. T. (1984). A comparison of skill-enhancement interventions with step-parenting couples (Doctoral dissertation, University of Oregon, 1984). Dissertation Abstracts International, 45, 3549A.

*Jessee, R. E., \& Guerney, B. G., Jr. (1981). A comparison of Gestalt and relationship enhancement treatments with married couples. The American Journal of Family Therapy, 9, 31-41.

*Joanning, H. (1982). The long-term effects of the Couple Communication Program. Journal of Marital and Family Therapy, 8, 463-468.

*Kaiser, A., Hahlweg, K., Fehm-Wolfsdorf, G., \& Groth, T. (1998). The efficacy of a compact psychoeducational group training program for married couples. Journal of Consulting and Clinical Psychology, 66, 753-760.

*Kaiser, A., Hahlweg, K., Fehm-Wolfsdorf, G., \& Groth, T. (1999). Indizierte Prävention bei BeziehungsstörungenEvaluation eines psychoedukativen Kompakt-programmes für Paare [Indicated prevention for longer married couples: Efficacy of a compact group program]. Verhaltenstherapie, 9, 76-85.

Kelly, A. B., Fincham, F. D., \& Beach, S. R. H. (2003). Communication skills in couples: A review and discussion of emerging perspectives. In B. R. Burleson \& J. O. Green (Eds.), Handbook of communication and social interaction skills (pp. 723-751). Mahwah, NJ: Erlbaum.

*Lane, M. T. (1993). An evaluation of a self-instructional marital enrichment training program (Doctoral dissertation, McGill University, 1993). Dissertation Abstracts International, 55, 1531A.

*Larson, K. B. (1976). The effects of communication training in small groups upon self-disclosure, marital adjustment, and emotional attachment in marriage (Doctoral dissertation, The University of Utah, 1976). Dissertation Abstracts International, 37, 5328B.

*Laurenceau, J. P., Stanley, S. M., Olmos-Gallo, A., Baucom, B., \& Markman, H. J. (2004). Community-based prevention of marital dysfunction: Multilevel modeling of a randomized effectiveness study. Journal of Consulting and Clinical Psychology, 72, 933-943.

Lipsey, M. W., \& Wilson, D. B. (2001). Practical meta-analysis. Thousand Oaks, CA: Sage.

*Long, E. C. J. (2000). [A longitudinal assessment of an empathy training program for couples in romantic relationships]. Unpublished raw data.

Lorenz, F. O., Melby, J. N., Conger, R. D., \& Xu, X. (2007). The effects of context on the correspondence between observational ratings and questionnaire reports of hostile behavior: A multitrait, multimethod approach. Journal of Family Psychology, 21, 498-509.

Markman, H. J., \& Floyd, F. (1980). Possibilities for the prevention of marital discord: A behavioral perspective. American Journal of Family Therapy, 8, 29-48.

*Markman, H. J., Floyd, F. J., Stanley, S. M., \& Storaasli, R. D. (1988). Prevention of marital distress: A longitudinal investigation. Journal of Consulting and Clinical Psychology, 56, 210 217.

*Meadors, R. E. (1989). Marriage enrichment: An emerging specialty of prevention in the field of marital counseling (Doctoral dissertation, Southern Illinois University at Carbondale, 1989). Dissertation Abstracts International, 51, 2270A.

*Meadors, W. K. (1994). The effects of a partially structured marriage enrichment weekend program on couples' perception of marital communication and adjustment changes (Doctoral dissertation, Memphis State University, 1994). Dissertation Abstracts International, 55, 1192A.

*Milholland, T. A., \& Avery, A. W. (1982). Effects of marriage encounter on self-disclosure, trust and marital satisfaction. Journal of Marital and Family Therapy, 8, 87-89.

Miller, S. L., Nunnally, E. W., \& Wackman, D. B. (1975). Minnesota Couples Communication Program (MCCP): Premarital and marital groups. In D. H. L. Olson (Ed.), Treating relationships (pp. 21-39). Lake Mills, IA: Graphic.

*Most, R., \& Guerney, B., Jr. (1983). An empirical evaluation of the training of lay volunteer leaders for premarital relationship enhancement. Family Relations, 32, 239-251.

Mrazek, P. J., \& Haggerty, R. J. (1994). Reducing the risks for mental disorder: Frontiers for preventive intervention research. Washington DC: Institute of Medicine, National Academy Press. Nowak, C., \& Heinrichs, N. (2008). A comprehensive metaanalysis of Triple-P Positive Parenting program using hierarchical linear modeling: Effectiveness and moderating variables. Clinical Child and Family Psychological Review, 11, 114-144. Ochs, E., Graesch, A. P., Mittmann, A., Bradbury, T., \& Repetti, R. (2006). Video ethnography and ethnoarchaeological tracking. In M. P. Pitt-Catsouphes, E. E. Kossek, \& S. Sweet (Eds.), The work and family handbook: Multi-disciplinary perspectives, methods, and approaches (pp. 387-409). Mahwah, NJ: Erlbaum. 
*Oxford, M. C. (2003). Success: Satisfying unions through couples communication and enhancement skills: A secondary prevention and enhancement program for married couples (Doctoral dissertation, Texas A\&M University, 2003). Dissertation Abstracts International, 64, 4629B.

*Perlow, S. P. (1985). An evaluation of a weaning procedure in increasing the maintenance of a couple communication training program (Doctoral dissertation, De Paul University, 1985). Dissertation Abstracts International, 46, 3604A.

*Petch, J. F., Halford, W. K., \& Creedy, D. (2006). Promoting a positive transition to parenthood: A randomized controlled trial of the Couple Care for Parents program. Unpublished manuscript, Griffith University, Queensland, Australia.

*Pretorius, H. G., van Wyk, J. D., \& Scheppers, J. M. (1992). Die evaluering van 'n huweliksvoorbereidingsprogram [The evaluation of a marital preparation program]. South African Journal of Psychology, 22, 140-146.

*Ramsay, A. J. (1989). Marriage enrichment: The use of computers to teach communication skills (Doctoral dissertation, University of North Texas, 1989). Dissertation Abstracts International, 50, 2390A.

Reardon-Anderson, J., Stagner, M., Macomber, J. E., \& Murray, J. (2005). Systematic review of the impact of marriage and relationship programs. Washington, DC: Urban Institute. Retrieved February 5, 2006, from http://www.urban.org/url .cfm?ID $=411142$

*Ridley, C. A., Avery, A. W., Harrell, J. E., Haynes-Clements, L. A., \& McCunney, N. (1981). Mutual problem-solving skills training for premarital couples: A six-month follow-up. Journal of Applied Developmental Psychology, 2, 179-188.

*Ridley, C. A., \& Bain, A. B. (1983). The effects of a premarital relationship enhancement program on self-disclosure. Family Therapy, 10, 13-24.

*Ridley, C. A., Jorgensen, S. R., Morgan, A. G., \& Avery, A. W. (1982). Relationship enhancement with premarital couples: An assessment of effects on relationship quality. The American Journal of Family Therapy, 10, 41-48.

*Ridley, C. A., \& Nelson, R. R. (1984). The behavioral effects of training premarital couples in mutual problem solving skills. Journal of Social and Personal Relationships, 1, 197-210.

*Ripley, J. S., \& Worthington, E. L., Jr. (2002). Hope-focused and forgiveness-based group interventions to promote marital enrichment. Journal of Counseling \& Development, 80, 452-463.

Rishel, C. W. (2007). Evidence-based prevention practice in mental health: What is it and how do we get there? American Journal of Orthopsychiatry, 77, 153-164.

*Sager, D. E., \& Sager, W. G. (2005). SANCTUS marriage enrichment. The Family Journal: Counseling and Therapy for Couples and Families, 13, 212-218.

*Saiz, C. C. (2001). Teaching couples communication and problem-solving skills: A self-directed, videotaped version of the prevention relationship enhancement program (PREP) (Doctoral dissertation, University of Denver, 2001). Dissertation Abstracts International, 62, 2076B.

*Samko, M. R. (1976). Self-disclosure and marital communication as a function of participation in a marriage workshop and the subsequent use of a communication technique (Doctoral dissertation, California School of Professional Psychology, 1976). Dissertation Abstracts International, 38, 4478B.

*Sams, W. P. (1983). Marriage preparation: An experimental comparison of the Premarital Relationship Enhancement (PRE) and the Engaged Encounter (EE) programs (Doctoral Dissertation, The Pennsylvania State University, 1983). Dissertation Abstracts International, 44, 3207-3477.
*Schaffer, M. (1980). An evaluation of the Minnesota Couple Communication program upon communication of married couples (Doctoral dissertation, University of Southern Mississippi, 1980). Dissertation Abstracts International, 41, 4643B.

*Schilling, E. A., Baucom, D. H., Burnett, C. K., Allen, E. S., \& Ragland, L. (2003). Altering the course of marriage: The effect of PREP communication skills acquisition on couples' risk of becoming maritally distressed. Journal of Family Psychology, 17, 41-53.

Schwartz, C., Bode, R., Repucci, N., Becker, J., Sprangers, M., \& Fayers, P. (2006). The clinical significance of adaptation to changing health: A meta-analysis of response shift. Quality of Life Research, 15, 1533-1550.

*Schwartz, R. C. (1980). The relationship among communication style, self esteem, and the Couple Communication Program (Doctoral dissertation, Purdue University, 1980). Dissertation Abstracts International, 41, 3198.

Shadish, W. R., \& Baldwin, S. A. (2003). Meta-analysis of MFT interventions. Journal of Marital and Family Therapy, 29, 547570.

Shadish, W. R., Matt, G. E., Navarro, A. M., \& Phillips, G. (2000). The effects of psychological therapies under clinically representative conditions: A meta-analysis. Psychological Bulletin, 126, 512-529.

*Shapiro, A. F., \& Gottman, J. M. (2005). Effects on marriage of a psycho-communicative-educational intervention with couples undergoing the transition to parenthood, evaluation at 1-year post intervention. Journal of Family Communication, 5, 1-24.

Spitzberg, B. H. (2003). Methods of interpersonal skill assessment. In J. O. Greene \& B. R. Burleson (Eds.), Handbook of communication and social interaction skills (pp. 93-134). Mahwah, NJ: Erlbaum.

* Stafford, R. R. (1978). Attitude and behavior change in couples as a function of communication training (Doctoral dissertation, Texas Tech University, 1978). Dissertation Abstracts International, 39, 2526B. (UMI No. 78-19, 902)

*Stanley, S. M., Allen, E. S., Markman, H. J., Saiz, C. C., Bloomstrom, G., Thomas, R., et al. (2005). Dissemination and evaluation of marriage education in the Army. Family Process, 44, 187-201.

Stanley, S. M., Bradbury, T. N., \& Markman, H. J. (2000). Structural flaws in the bridge from basic research on marriage to interventions for couples: Illustrations from Gottman, Coan, Carrere, and Swanson (1998). Journal of Marriage and the Family, 62, 256-264.

*Steller, J. B. (1979). The effects of Couples Communication training upon individualized goals, marriage adjustment, self disclosure, and the use of communication skills by married couples (Doctoral dissertation, University of Minnesota, 1979). Dissertation Abstracts International, 40, 900B.

*Strickland, J. H. (1981). The effects of two marriage enrichment retreat models on marital satisfaction (Doctoral Dissertation, Texas Tech University, 1981). Dissertation Abstracts International, 42(10-A), 4305.

*Thompson, K. B. (1978). The effectiveness of Couples Communication training on interpersonal orientation, couple communication, perceptual congruence, and verbal communication style: A field study (Doctoral dissertation, University of Iowa, 1978) Dissertation Abstracts International, 39, 3009B.

*Trathen, D. W. (1995). A comparison of the effectiveness of two Christian premarital counseling programs (skills and information based) utilized by evangelical protestant churches (Doctoral dissertation, University of Denver, 1995). Dissertation Abstracts International, 56, 2277A. 
*Turner, L. (1998). The impact of a psychoeducational group intervention on marital discord, adult interaction style, projective identification, and perceptive identification (Doctoral dissertation, The Catholic University of America, 1998). Dissertation Abstracts International, 59, 1337-1647.

*Valenti, F. T. (1987). Effects of the Couple Communication Program 1 on the marital adjustment, self-disclosure, and communication style of therapy and non-therapy participants (Doctoral dissertation, The University of North Carolina at Greensboro, 1987). Dissertation Abstracts International, 49, 1715A.

*van der Molen, H. T., Gramsbergen-Hoogland, Y., Wolters, F. J. M., \& de Meijer, M. (1987). Effecten van een communicatie-cursus voor (echt) paren [Effects of a communication course for married couples]. Tijdschrift Voor Psychotherapie, 13, 114-127.

*Van Widenfelt, B., Hosman, C., Schaap, C., \& van der Staak, C. (1996). The prevention of relationship distress for couples at risk: A controlled evaluation with nine-month and two-year followups. Family Relations, 45, 156-165.

*Vijayalakshmi, O. P. (1997). Enriching marital communication and marital adjustment of couples from India living in the United States (Doctoral dissertation, Oregon State University, 1997). Dissertation Abstracts International, 58, 1605A.

*Wampler, K. S., \& Sprenkle, D. H. (1980). The Minnesota Couple Communication Program: A follow-up study. Journal of Marriage and the Family, 42, 577-584.

*Warner, M. D. (1981). Comparison of a religious marriage enrichment program with an established communication training enrichment program (Doctoral dissertation, Purdue University, 1981). Dissertation Abstracts International, 42, 3774A.

Weissberg, R. P., Kumpfer, K. L., \& Seligman, M. E. P. (2003). Prevention that works for children and youth. American Psychologist, 58, 425-432.
*Wilkinson, L. L. H. (1983). Consensus model training for couples: An outcome study of an integrated conflict management program for marriage enrichment (Doctoral dissertation, University of Colorado at Boulder, 1983). Dissertation Abstracts International, 44, 993A.

*Wilson, D. A. (1980). The effects of a partially structured Christian marriage enrichment program upon marital communication, general marital adjustment, and purpose in life (Master's thesis, North Texas State University, 1980). Dissertation Abstracts International, 41, 1506-1707.

*Witkin, S. L., Edleson, J. L., Rose, S. D., \& Hall, J. A. (1983). Group training in marital communication: A comparative study. Journal of Marriage and the Family, 45, 661-669.

*Wong, J. T. (2003). Evaluation of a church-based marriage preparation course: A preliminary study (Doctoral dissertation, Fuller Theological Seminary, 2003). Dissertation Abstracts International, 65, 3735B

*Worthington, E. L., Jr., Buston, B. G., \& Hammonds, T. M. (1989). A component analysis of marriage enrichment: Information and treatment modality. Journal of Counseling and Development, 67, 555-560.

*Wu, D. J. (1999). Developing and Implementing a Christian marriage enrichment program for Chinese immigrants (Doctoral dissertation, Asbury Theological Seminary, 1999). Dissertation Abstracts International, 60, 1785A.

*Yarbrough, D. M. (1983). Effects of structured negotiation training on dyadic adjustment, satisfaction, and intimacy (Doctoral dissertation, University of Georgia, 1983). Dissertation Abstracts International, 44, 2422A.

Received March 25, 2008

Revision received November 21, 2008 Accepted December 3, 2008 